\title{
Impact of Prophylactic Noninvasive Ventilation on Extubation Outcome: A 4-year Prospective Observational Study from a Multidisciplinary ICU
}

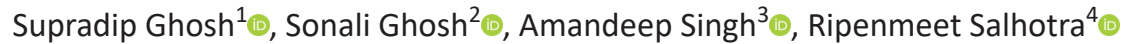

\begin{abstract}
Introduction: With emerging evidence supporting other interventions, there is a need to re-examine the safety and efficacy of postextubation noninvasive ventilation (NIV) support in high-risk patients.

Methods: Data were collected over 4-year period from a multispeciality ICU. High-risk criteria were uniform, and the application of NIV was protocolized. Successful extubation was defined as the absence of both reintubation and NIV support at 72 hours postextubation.

Results: Extubation success was achieved in $79.6 \%$. At extubation, more patients in the failure group had chronic neurological or kidney diseases, longer days of invasive ventilation, higher sequential organ failure assessment score, and more positive fluid balance. Significant differences were also observed in the indications for prophylactic NIV between the two groups. However, in logistic regression analysis, none of these differences observed in univariate analysis was independently associated with extubation outcome. Failure of postextubation NIV was associated with higher hospital mortality ( 67.7 vs 10.7\%, $p<0.001)$ and longer ICU/hospital length of stay (median 10 vs 6 days, $p<0.001$ and 13 vs 10 days, $p<0.01$, respectively). No differences were observed in extubation outcomes between 2016 to 2017 and 2018 to 2019 cohorts. Conclusion: High rate of extubation failure and worse patient-centric outcomes associated with prophylactic NIV calls for a relook into the current recommendation of NIV for this indication.

Keywords: Efficacy of prophylactic noninvasive ventilation, High risk of extubation failure, Weaning.

Indian Journal of Critical Care Medicine (2021): 10.5005/jp-journals-10071-23880
\end{abstract}

\section{INTRODUCTION}

A recent guideline from the European Respiratory Society and American Thoracic Society had given a conditional recommendation to postextubation noninvasive ventilation (NIV) support in high- risk patients. ' However, the guideline accepted low certainty of evidence supporting this recommendation. Several factors could contribute to this uncertainty, including variable criteria used to define high-risk patients, substantial variations observed in rates of reintubation and time to reintubation in NIV arms, and absence of uniform reintubation criteria in many of these studies..$^{2-4}$ Perhaps this uncertainty around the evidence is responsible for the failure of this strategy to gain widespread acceptance in clinical practice. ${ }^{5}$ To complicate the matter further, failure of prophylactic NIV is demonstrated to be associated with worsening of organ dysfunction, more adverse events, and an increase in-hospital mortality. ${ }^{6}$ More recently, high flow nasal oxygenation (HFNO) is gaining popularity as postextubation respiratory support with noninferiority of HFNO (vs NIV) demonstrated in preventing postextubation respiratory failure. ${ }^{7,8} \mathrm{Combining} \mathrm{HFNO}$ and NIV is found to be even better than HFNO alone. ${ }^{9}$

We conducted a prospective observational study of patients at high risk of postextubation respiratory failure and in whom prophylactic NIV support was applied postextubation. The aims of our study were to document extubation outcome in high-risk patients on postextubation NIV in real-world scenario, to identify subgroups of patients who might be benefited specifically by this strategy, and to determine the potential impact of the experience of the team on extubation outcome. To test the latter hypothesis, we planned to compare extubation data from two different study periods: 2016 to 2017 and 2018 to 2019.
1,3,4 Department of Critical Care Medicine, Fortis-Escorts Hospital, Faridabad, Haryana, India

${ }^{2}$ Department of Paediatric Critical Care, QRG Medicare, Faridabad, Haryana, India

Corresponding Author: Supradip Ghosh, Department of Critical Care Medicine, Fortis-Escorts Hospital, Faridabad, Haryana, India, Phone: +91-9818590021, e-mail: intensivist1972@gmail.com

How to cite this article: Ghosh S, Ghosh S, Singh A, Salhotra R. Impact of Prophylactic Noninvasive Ventilation on Extubation Outcome: A 4-year Prospective Observational Study from a Multidisciplinary ICU. Indian J Crit Care Med 2021;25(6):709-714.

Source of support: Nil

Conflict of interest: None

\section{Methods}

The study was conducted in the 18-bed multidisciplinary ICU of Fortis-Escorts Hospital, Faridabad, India. Patients' data were collected prospectively for a period between January 1, 2016, and December 31, 2019. Part of these data were reported in two earlier publications. ${ }^{6,10}$ Institutional ethics committee approval was obtained for both studies and consents of patients' relatives were obtained before enrolment. Inclusion criteria for study entry were consenting adult ( $>18$ years) patients who had planned extubation following invasive ventilation for at least 24 hours and who were put on NIV support postextubation for any one of the following high-risk criteria: underlying chronic obstructive airway disease (COAD) with $\mathrm{PaCO}_{2}>45 \mathrm{~mm} \mathrm{Hg}$ at extubation,

( ) Jaypee Brothers Medical Publishers. 2021 Open Access This article is distributed under the terms of the Creative Commons Attribution 4.0 International License (https://creativecommons.org/licenses/by-nc/4.0/), which permits unrestricted use, distribution, and non-commercial reproduction in any medium, provided you give appropriate credit to the original author(s) and the source, provide a link to the Creative Commons license, and indicate if changes were made. The Creative Commons Public Domain Dedication waiver (http://creativecommons.org/publicdomain/zero/1.0/) applies to the data made available in this article, unless otherwise stated. 
age $>65$ years, history of chronic heart failure (New York Heart Association class II-IV) or left ventricular ejection fraction $<40 \%$, prior failed spontaneous breathing trial or two or more organ system failure other than chronic respiratory or heart failure. Only the first episode of extubation was included for analysis. Patients were excluded from the study if they have any of the following conditions: contraindications to NIV application (example: craniofacial trauma or surgery, ongoing upper gastrointestinal bleeding, excessive respiratory secretions or inability to handle secretion, recurrent vomiting, recent gastric or esophageal surgery, tracheostomized, etc) or patients who are already on home NIV or patients with the decision to limit therapeutic intervention or refusal to consent.

\section{Procedure}

The weaning process of the unit has already been described earlier. ${ }^{10}$ Prophylactic NIV support was started immediately postextubation. Protocol for NIV application has been published previously. ${ }^{6}$ Initially NIV support was applied almost continuously for 6 to 12 hours except for 15 to 20 minutes periods to allow the patient to drink fluids or receive nursing care. Unassisted periods of breathing were allowed for a gradually increasing period following initial 6 to 12 hours of NIV support; provided the patient was comfortable and was able to maintain adequate oxygenation and $\mathrm{pH}$ remained $>7.35$. Either a need for reintubation within 72 hours or a continued requirement of NIV at 72 hours postextubation was categorized as extubation failure. Criteria for reintubation broadly followed international guidelines. ${ }^{11}$ However, the final decision regarding both discontinuation of NIV and reintubation was left to the discretion of the attending intensivist.

\section{Data Collection}

The data collection process was uniform and was described in our previous publication. ${ }^{6}$ All relevant data were collected both at intubation and at the time of extubation. Time to reintubation (from the time of extubation) and indications for reintubation were recorded for patients requiring reintubation. Following outcome data were recorded at hospital discharge: total duration of prophylactic NIV, the outcome of extubation (success or failure), adverse effects of NIV (intolerance to mask, conjunctival irritation, pressure effect, abdominal distension, or agitation), and ICU or hospital length of stay (LOS). The outcome of hospitalization was recorded as survival or death, and the worst possible outcome (death) was recorded as the hospital outcome for patients in whom family wished to discontinue further treatment.

\section{Statistical Analysis Plan}

Data were summarized and an appropriate statistical test was applied based on the type and distribution of data. The level of statistical significance was fixed as two-tailed $p$-values of $<0.05$. For univariate analysis, patients with extubation success and failure (from the whole cohort) were compared for variables both at intubation and at the time of extubation. Conditional stepwise multivariable logistic regression analysis was performed to identify independent factors related to extubation outcome. Patient-centric outcomes were also compared between failure and success groups.

To evaluate the effect of experience in using NIV on extubation outcome, baseline variable at the time of intubation and at extubation was compared for two different time periods-period 1 (between January 1, 2016, and December 31, 2017) and period 2 (between January 1, 2018, and December 31, 2019). Logistic regression analysis was performed to negate the effect of any difference in baseline variables. To assess the time to reintubation and cumulative hazard of reintubation between two time periods, Kaplan-Meier curve was plotted. Data were compared using a logrank test. For statistical analysis, SPSS software version 22.0 (SPSS, Chicago, Illinois) was used.

\section{Results \\ At Intubation}

A total of 152 patients were eligible for data analysis. Of 152 patients, 121 (79.6\%) had successful extubation at 72 hours by study definition. The median time to reintubation was 24.5 hours [interquartile range, Q1, Q3, 7.1, 36.5 hours]. Reasons for reintubation were refractory hypoxia $(11,36.7 \%)$, worsening hypercapnia (8, $26.7 \%)$, airway issues $(6,20 \%)$, extreme agitation $(4,13.3 \%)$, and refractory hypotension (1,3.3\%). More patients in the failure group had underlying chronic kidney and neurological conditions, higher sequential organ failure assessment score at intubation, longer time on invasive ventilation, and higher fluid balance at extubation. A significant difference was observed in indications for NIV. Table 1 compares baseline parameters between extubation success and failure groups. However, in logistic regression analysis, none of these variables were found to be independently associated with extubation outcomes.

\section{Clinical Outcome}

Table 2 shows the comparison in clinical outcome between successfully extubated patients and patients with extubation failure. Patients with extubation success spent more time on NIV (median 26 vs 19 hours, $p<0.01$ ). The success group also had lower hospital mortality compared to the failure group (10.7 vs $67.7 \%$, $p$ <0.001). Extubation success was also associated with shorter ICU, as well as hospital LOS. A higher incidence of adverse effects was observed in the extubation failure group ( 45.2 vs $9.9 \%, p<0.001$ ) and was mostly related to extreme agitation.

\section{Extubation Success in Two Different Time Periods}

Numerically higher percentage of patients had extubation success in 2018 to 2019 cohort compared to 2016 to 2017 cohort, but the difference did not meet statistical significance (84.7 vs $76.3 \%$, $p=0.21$ ). In univariate analysis, significant differences were observed in baseline and at extubation parameters between two cohortsgender, chronic cardiac/respiratory disease, on admission APACHE $\mathrm{II}$, intubation indication, mean arterial pressure, $\mathrm{pH}, \mathrm{PaCO}_{2}$, and fluid balance at extubation (Table 3). However, the difference in extubation success between two cohorts remained statistically nonsignificant even after adjustment for differences observed in univariate analysis. The cumulative hazard of reintubation was not different between the two cohorts in Kaplan-Meier analysis ( $p=0.19)$ (Fig. 1).

\section{Discussion}

From this relatively large cohort, we observed that in high-risk patients extubation failure rate remains high despite the use of prophylactic NIV in a protocolized manner. We did not observe any subgroup of patients who might be particularly benefited from prophylactic NIV. Extubation failure is shown to be clearly associated with worse patient outcomes. With no significant difference in extubation outcome observed in two consecutive study periods, it is unlikely that outcome of prophylactic NIV would improve further with experience beyond the basic level of training. 
Table 1: Variables at initial intubation and extubation in extubation success and failure groups

\begin{tabular}{|c|c|c|c|c|}
\hline Parameter & Total $(N=152)$ & Success $(N=121)$ & Failure $(N=31)$ & $p$ value \\
\hline Age in years (mean $\pm S D)$ & $64.54 \pm 14.09$ & $63.98 \pm 13.71$ & $66.71 \pm 15.52$ & 0.33 \\
\hline Female sex, no. (\%) & $67(44.1 \%)$ & $50(41.3 \%)$ & $17(54.8 \%)$ & 0.09 \\
\hline Source of admission & & & & 0.17 \\
\hline Emergency department, no. (\%) & $121(79.6 \%)$ & $100(82.6 \%)$ & $21(67.7 \%)$ & \\
\hline Operation theater, no. (\%) & $2(1.3 \%)$ & $2(1.7 \%)$ & 0 & \\
\hline Wards, no. (\%) & $29(19.1 \%)$ & $19(15.7 \%)$ & $10(32.3 \%)$ & \\
\hline Admission category & & & & 0.66 \\
\hline Medical, no. (\%) & 147 (96.7\%) & $117(96.7 \%)$ & $30(96.8 \%)$ & \\
\hline Postoperative, no. (\%) & $3(2 \%)$ & $2(1.7 \%)$ & $1(3.2 \%)$ & \\
\hline Trauma, no. (\%) & $2(1.3 \%)$ & $2(1.7 \%)$ & 0 & \\
\hline Chronic cardiac disease, no. (\%) & $24(15.8 \%)$ & $17(14 \%)$ & $7(22.6 \%)$ & 0.24 \\
\hline Chronic respiratory disease, no. (\%) & 107 (70.4\%) & $86(71.1 \%)$ & $21(67.7 \%)$ & 0.71 \\
\hline Chronic kidney disease, no. (\%) & $13(8.6 \%)$ & $7(5.8 \%)$ & $6(19.4 \%)$ & 0.01 \\
\hline Chronic neurological disease, no. (\%) & $13(8.6 \%)$ & $6(5 \%)$ & $7(22.6 \%)$ & $<0.01$ \\
\hline APACHE II score on day of intubation (median, IQR) & $18(14,25)$ & $18(13.5,24)$ & $20(16,26)$ & 0.21 \\
\hline Indications for intubation, no. (\%) & & & & 0.1 \\
\hline Poor GCS, no. (\%) & $9(5.9 \%)$ & $6(5 \%)$ & $3(9.7 \%)$ & \\
\hline Hypoxemic respiratory failure, no. (\%) & $34(22.4 \%)$ & $31(25.6 \%)$ & $3(9.7 \%)$ & \\
\hline Hypercapnic respiratory failure, no. (\%) & $95(62.5 \%)$ & $75(62 \%)$ & $20(64.5 \%)$ & \\
\hline Worsening shock, no. (\%) & $8(5.3 \%)$ & $5(4.1 \%)$ & $3(9.7 \%)$ & \\
\hline Postoperative, no. (\%) & $5(3.3 \%)$ & $4(3.3 \%)$ & $1(3.2 \%)$ & \\
\hline Airway issues, no. (\%) & $1(0.7 \%)$ & 0 & $1(3.2 \%)$ & \\
\hline $\begin{array}{l}\text { Invasive ventilation days before extubation } \\
\text { (median, IQR) }\end{array}$ & $2.5(1.75,4)$ & $2.25(1.75)$ & $3.25(2,6)$ & $<0.01$ \\
\hline SBT—PS/CPAP, no (\%) & $137(90.1 \%)$ & $110(90.9 \%)$ & $27(87.1 \%)$ & 0.5 \\
\hline SOFA score on day of extubation (median, IQR) & $3(2,5)$ & $3(2,4)$ & $5(3,6)$ & $<0.001$ \\
\hline Heart rate/minute at extubation (mean \pm SD) & $97.89 \pm 16.62$ & $96.92 \pm 16.45$ & $101.71 \pm 17.01$ & 0.16 \\
\hline Respiratory rate/minute at extubation (mean \pm SD) & $24.03 \pm 4.33$ & $23.97 \pm 4.21$ & $24.29 \pm 4.85$ & 0.73 \\
\hline Mean arterial pressure at extubation (mean $\pm S D$ ) & $89.28 \pm 15.35$ & $88.60 \pm 15.34$ & $91.90 \pm 15.35$ & 0.29 \\
\hline $\mathrm{pH}$ at extubation (mean $\pm \mathrm{SD}$ ) & $7.39 \pm 0.05$ & $7.39 \pm 0.05$ & $7.40 \pm 0.05$ & 0.9 \\
\hline $\mathrm{PaCO}_{2}$ in $\mathrm{mm} \mathrm{Hg}$ at extubation (mean $\pm \mathrm{SD}$ ) & $48.46 \pm 11.78$ & $49.16 \pm 12.21$ & $45.72 \pm 9.63$ & 0.1 \\
\hline $\mathrm{PaO}_{2} / \mathrm{FiO}_{2}$ ratio at extubation (median, IQR) & $212(186,264.5)$ & $212(184,256)$ & $220(195,300)$ & 0.19 \\
\hline Lactate in $\mathrm{mmol} / \mathrm{L}$ at extubation (median, IQR) & $0.9(0.7,1.2)$ & $1(0.7,1.2)$ & $0.8(0.6,1.2)$ & 0.08 \\
\hline Cumulative fluid balance in $\mathrm{mL}$ (median, IQR) & $2731.5(1009.25,4820)$ & $2307(1018.5,4063.5)$ & $4855(1000,7123)$ & 0.01 \\
\hline Indications for prophylactic NIV, no. (\%) & & & & $<0.01$ \\
\hline COAD with $\mathrm{PaCO}_{2}>45 \mathrm{~mm} \mathrm{Hg}$ at extubation, no. (\%) & $61(40.1 \%)$ & $54(44.6 \%)$ & $7(22.6 \%)$ & \\
\hline $\begin{array}{l}\text { Age }>65 \text { years with or without chronic cardiac or } \\
\text { respiratory illness, no. (\%) }\end{array}$ & $30(19.7 \%)$ & $27(22.3 \%)$ & $2(20 \%)$ & \\
\hline History of CHF or LVEF $<40 \%$, no. (\%) & $13(8.6 \%)$ & $12(9.9 \%)$ & $1(3.2 \%)$ & \\
\hline Prior failed SBT, no. (\%) & $13(8.6 \%)$ & $7(5.8 \%)$ & $6(19.4 \%)$ & \\
\hline $\begin{array}{l}\text { Two or more organ system failure other than chronic } \\
\text { respiratory or heart failure, no. (\%) }\end{array}$ & $35(23 \%)$ & $21(17.4 \%)$ & $14(45.2 \%)$ & \\
\hline
\end{tabular}

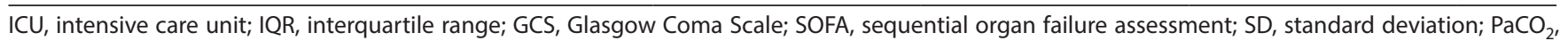
partial pressure of carbon dioxide; $\mathrm{PaO}_{2} / \mathrm{FiO}_{2}$, a ratio of partial pressure of oxygen and fractional inspiratory oxygen; NIV, noninvasive ventilation; COAD, chronic obstructive airway disease; $\mathrm{CHF}$, congestive heart failure; LVEF, left ventricular ejection fraction 
Table 2: Patient outcome

\begin{tabular}{|c|c|c|c|c|}
\hline Parameter & Total $(N=152)$ & Success $(N=75)$ & Failure $(N=10)$ & pvalue \\
\hline Duration of NIV support in hours (median, IQR) & $24.5(18,38)$ & $26(18,38)$ & $19(6,30)$ & $<0.01$ \\
\hline Adverse effects, no (\%) & $26(17.1 \%)$ & $12(9.9 \%)$ & $14(45.2 \%)$ & $<0.001$ \\
\hline Extreme agitation requiring sedation, no (\%) & $17(11.2 \%)$ & $3(2.5 \%)$ & $14(45.2 \%)$ & \\
\hline Conjunctival irritation, no (\%) & $3(2 \%)$ & $3(2.5 \%)$ & $0(0 \%)$ & \\
\hline Mask intolerance, no (\%) & $3(2 \%)$ & $3(2 \%)$ & $0(0 \%)$ & \\
\hline Nasal bridge ulceration, no (\%) & $2(1.3 \%)$ & $2(1.7 \%)$ & $0(0 \%)$ & \\
\hline Abdominal distension, no (\%) & $1(0.7 \%)$ & $1(0.8 \%)$ & $0(0 \%)$ & \\
\hline In-hospital mortality, no (\%) & $34(22.4 \%)$ & $13(10.7 \%)$ & $21(67.7 \%)$ & $<0.001$ \\
\hline ICU length of stay in days (median, IQR) & $6(4.25,9)$ & $6(4,8)$ & $10(7,21)$ & $<0.001$ \\
\hline Hospital length of stay in days (median, IQR) & $10(8,15)$ & $10(8,13)$ & $13(8,21)$ & 0.01 \\
\hline
\end{tabular}

Table 3: Comparison between 2016 to 2017 and 2018 to 2019 cohort

\begin{tabular}{|c|c|c|c|c|}
\hline Parameters & Total $(N=152)$ & $2016-2017(N=93)$ & $2018-2019(N=59)$ & $p$ value \\
\hline Extubation success, no (\%) & $121(79.6 \%)$ & $71(76.3 \%)$ & $50(84.7 \%)$ & 0.21 \\
\hline Age (mean $\pm S D)$ & $64.54 \pm 14.09$ & $63.46 \pm 15.40$ & $66.24 \pm 11.65$ & 0.21 \\
\hline Female sex, no (\%) & $67(44.1 \%)$ & $49(52.7 \%)$ & $18(30.5 \%)$ & $<0.01$ \\
\hline Source of admission & & & & 0.44 \\
\hline Emergency department, no. (\%) & $121(79.6 \%)$ & $72(77.4 \%)$ & $49(83.1 \%)$ & \\
\hline Operation theater, no. (\%) & $2(1.3 \%)$ & $2(2.2 \%)$ & $0(0 \%)$ & \\
\hline Wards, no. (\%) & $29(19.1 \%)$ & $19(20.4 \%)$ & $10(16.9 \%)$ & \\
\hline Admission category & & & & 0.19 \\
\hline Medical, no (\%) & 147 (96.7\%) & $88(94.6 \%)$ & 59 (100\%) & \\
\hline Postoperative, no (\%) & $3(2 \%)$ & $3(3.2 \%)$ & $0(0 \%)$ & \\
\hline Trauma, no (\%) & $2(1.3 \%)$ & $2(2.2 \%)$ & $0(0 \%)$ & \\
\hline Chronic cardiac disease, no (\%) & $24(15.8 \%)$ & $19(20.4 \%)$ & $5(8.5 \%)$ & 0.04 \\
\hline Chronic respiratory disease, no (\%) & 107 (70.4\%) & $55(59.1 \%)$ & $52(88.1 \%)$ & $<0.001$ \\
\hline Chronic kidney disease, no (\%) & $13(8.6 \%)$ & $7(7.5 \%)$ & $6(10.2 \%)$ & 0.57 \\
\hline Chronic neurological disease, no (\%) & $13(8.6 \%)$ & $11(11.8 \%)$ & $2(3.4 \%)$ & 0.07 \\
\hline APACHE II score on the day of intubation (median, IQR) & $18(14,25)$ & $21(15.5,27)$ & $14(10,21)$ & $<0.001$ \\
\hline Indication for intubation, no (\%) & & & & 0.01 \\
\hline Poor GCS, no (\%) & $9(5.9 \%)$ & $7(7.5 \%)$ & $2(3.4 \%)$ & \\
\hline Hypoxemic respiratory failure, no (\%) & $34(22.4 \%)$ & $25(26.9 \%)$ & $9(15.3 \%)$ & \\
\hline Hypercapnic respiratory failure, no (\%) & $95(62.5 \%)$ & $48(51.6 \%)$ & $47(79.7 \%)$ & \\
\hline Worsening shock, no (\%) & $8(5.3 \%)$ & $7(7.5 \%)$ & $1(1.7 \%)$ & \\
\hline Postoperative, no (\%) & $5(3.3 \%)$ & $5(5.4 \%)$ & $0(0 \%)$ & \\
\hline Airway issues, no (\%) & $1(0.7 \%)$ & $1(1.1 \%)$ & $0(0 \%)$ & \\
\hline \multicolumn{5}{|l|}{ Parameters at extubation } \\
\hline Invasive ventilation days (IQR) & $2.5(1.75,4)$ & $2.5(1.75,4.25)$ & $2.5(1.75,3)$ & 0.32 \\
\hline SBT—PS/CPAP, no (\%) & $137(90.1 \%)$ & $86(92.5 \%)$ & $51(86.4 \%)$ & 0.22 \\
\hline SOFA on day of extubation (median, IQR) & $3(2,5)$ & $3(2,5)$ & $3(2,4)$ & 0.08 \\
\hline Heart rate/minute (mean $\pm \mathrm{SD}$ ) & $97.89 \pm 16.62$ & $98.74 \pm 17.82$ & $96.56 \pm 14.58$ & 0.41 \\
\hline Respiratory rate/minute (mean $\pm \mathrm{SD}$ ) & $24.03 \pm 4.33$ & $24.17 \pm 4.78$ & $23.81 \pm 3.54$ & 0.59 \\
\hline Mean arterial pressure (mean $\pm \mathrm{SD})$ & $89.28 \pm 15.35$ & $92.10 \pm 15.49$ & $84.83 \pm 14.14$ & $<0.01$ \\
\hline $\mathrm{pH}($ mean $\pm \mathrm{SD})$ & $7.39 \pm 0.05$ & $7.39 \pm 0.05$ & $7.40 \pm 0.05$ & 0.02 \\
\hline $\mathrm{PaCO}_{2}$ in $\mathrm{mm} \mathrm{Hg}($ mean $\pm \mathrm{SD})$ & $48.46 \pm 11.78$ & $46.91 \pm 11.81$ & $50.90 \pm 10.52$ & 0.04 \\
\hline $\mathrm{PaO}_{2} / \mathrm{FiO}_{2}$ ratio (median, IQR) & $212(186,264.5)$ & $210(181,288)$ & $212(193,250)$ & 0.61 \\
\hline \multirow[t]{2}{*}{ Lactate in $\mathrm{mmol} / \mathrm{L}($ mean $\pm \mathrm{SD})$} & $1 \pm 0.56$ & $1.08 \pm 0.63$ & $0.88 \pm 0.41$ & 0.11 \\
\hline & & & & \\
\hline Indian Journal of Critical Care Medicine, Volume 25 & ssue 6 (June 2021) & & & \\
\hline
\end{tabular}




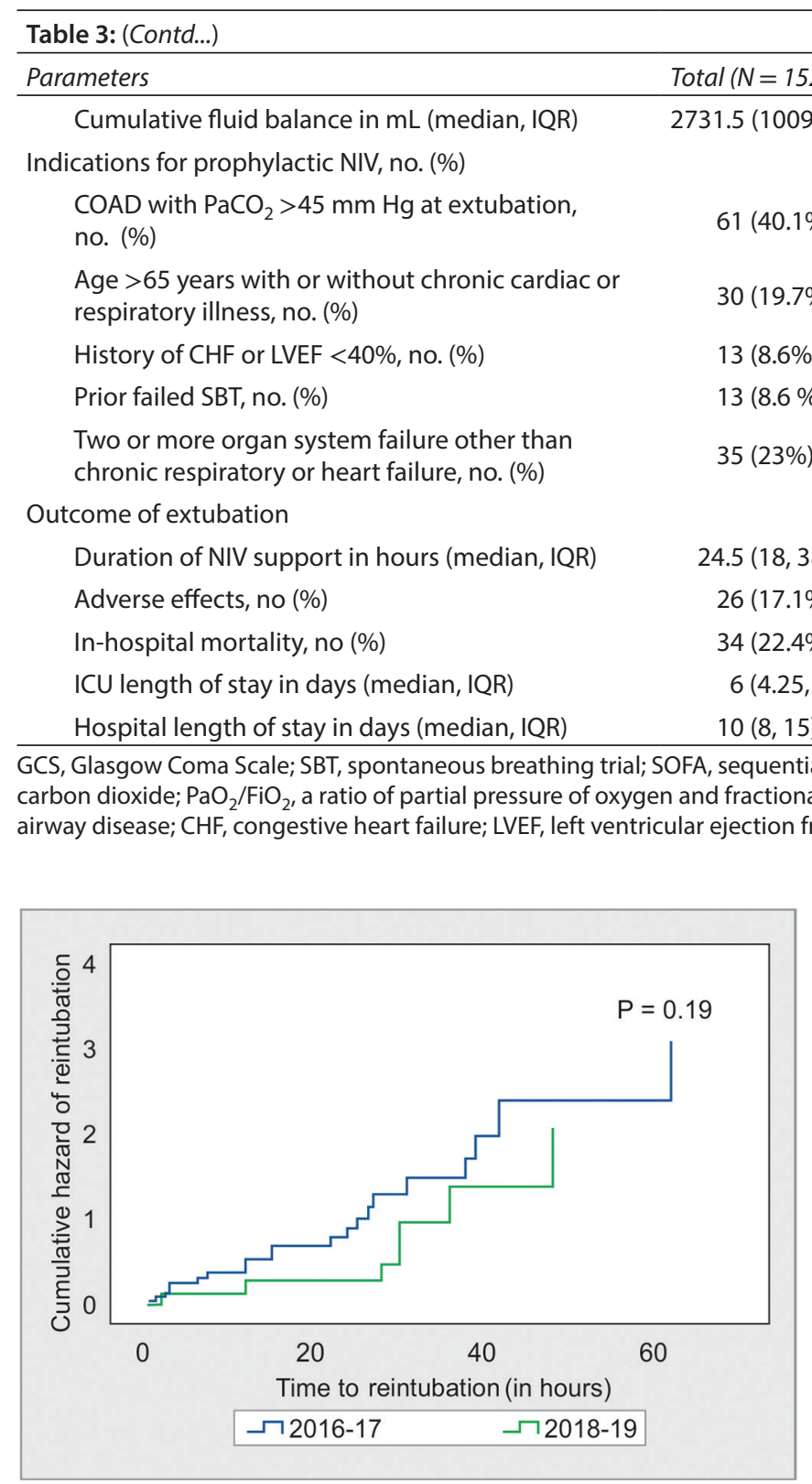

Fig. 1: Cumulative hazard of reintubation after 72 hours, by using the Kaplan-Meier curve. $p$ value obtained with the log-rank test

\section{Experience from Randomized Studies}

Nava and colleagues randomized 97 high-risk patients to either NIV or low flow oxygen. ${ }^{2}$ NIV was applied 1 hour after successful extubation. ${ }^{2}$ Rate of reintubation and ICU mortality were lower in the NIV group. This result, however, was not replicated in the study by Ferrer and colleagues with similar reintubation rate and ICU or 90-day mortality observed between NIV and control groups. ${ }^{3}$ Interestingly, mortality benefit was observed in a subgroup of patients with underlying chronic respiratory disease and hypercapnia at extubation. ${ }^{3}$ This latter observation was tested in a subsequent study by the same group. ${ }^{4}$ In 102 patients with chronic respiratory disease and hypercapnia at extubation, application of prophylactic NIV was associated with higher extubation success. ${ }^{4}$ Lower 90-day mortality observed in the NIV group despite no difference in short-term ICU or in-hospital mortality, however, remains unexplained. ${ }^{4}$

In cardiac surgery patients, Stephan and colleagues compared NIV with HFNO for mixed indications (including facilitating extubation, as prophylaxis, and as a management strategy for respiratory failure postextubation) and demonstrated HFNO to be noninferior to NIV in preventing extubation failure. ${ }^{7}$ In the study by Hernandez and colleagues, the rate of reintubation was similar between HFNO and NIV groups in high-risk patients. ${ }^{8}$

\section{Comparison of RCT Data with Present Study}

We used uniform criteria to define high risk, based on earlier published data. ${ }^{2,12}$ Rate of extubation failure (20.4\%) in our patients was higher compared to NIV arms of studies comparing NIV with low flow oxygen ( $8 \%$ in Nava study, ${ }^{2} 16 \%$ in the first study by Ferrer, ${ }^{3}$ and $15 \%$ in the second study by Ferrer ${ }^{4}$ ). However, our extubation failure rate is comparable with more contemporary studies comparing NIV with HFNO $(21.9 \%$ in Stephan study ${ }^{7}$ and $19.1 \%$ in Hernandez study ${ }^{8}$ ).

Patients who failed extubation attempts had significantly higher in-hospital mortality. One reason for this higher mortality could be potential delay in reintubation in patients on NIV. ${ }^{13,14}$ However, the median time to reintubation in our study ( 24.5 hours) was comparable to earlier studies that reported this parameter ( 41 hours in the first Ferrer study, ${ }^{3} 29$ hours in the second Ferrer study, ${ }^{4}$ and 21.5 hours in study by Hernandez ${ }^{8}$ ).

\section{Conclusion}

High rate of extubation failure and associated worse patient outcomes observed in our study raises concerns about the use of prophylactic NIV support in high-risk patients. In light of our findings, the current recommendation for prophylactic NIV for patients at high risk of extubation failure needs to be revisited. ${ }^{1,15}$ In view of recent evidence showing encouraging result of a 
combination of NIV support alternated with HFNO in preventing extubation failure, we suggest a future randomized study comparing NIV against combination strategy of NIV plus HFNO on extubation outcome in high-risk patients.

\section{ACKnowledgments}

We sincerely acknowledge the contributions of all staff members and doctors of the Intensive Care Unit, Fortis-Escorts Hospital, Faridabad for their support in conducting the study and in the clinical management of the patients. We are thankful to Dr. DK Shukla for the statistical analysis of the data.

\section{Individual Author Contribution}

- Dr. Supradip Ghosh. Conceptualization; Data curation; Formal analysis; Investigation; Methodology; Project administration; Resources; Software; Supervision; Validation; Visualization; Roles/Writing —original draft; Writing — review and editing.

- Dr. Sonali Ghosh. Formal analysis; Writing-review and editing.

- Dr. Amandeep Singh. Data curation; Writing-review and editing.

- Dr. Ripenmeet Salhotra. Data curation; Writing-review and editing.

- All authors take complete responsibility for the accuracy and integrity of all parts of the work.

\section{ORCID}

Supradip Ghosh @ https://orcid.org/0000-0002-7892-2078

Sonali Ghosh (1) https://orcid.org/0000-0002-2130-0630

Amandeep Singh (1) https://orcid.org/0000-0001-5399-4801

Ripenmeet Salhotra ㄴ https://orcid.org/0000-0001-8987-6102

\section{References}

1. Rochwerg B, Brochard L, Elliott MW, Hess D, Hill NS, Nava S, et al. Official ERS/ATS clinical practice guidelines: non-invasive ventilation for acute respiratory failure. Eur Respir J 2017;50(2):1602426. DOI: 10.1183/13993003.02426-2016.

2. Nava S, Gregoretti C, Fanfulla F, Squadrone E, Grassi M, Carlucci A, et al. Non-invasive ventilation to prevent respiratory failure after extubation in high-risk patients. Crit Care Med 2005;33(11):2465-2470. DOI: 10.1097/01.ccm.0000186416.44752.72.

3. Ferrer M, Valencia M, Nicolas JM, Bernadich O, Badia JR, Torres A. Early non-invasive ventilation averts extubation failure in patients at risk - a randomized trial. Am J Respir Crit Care Med 2006;173(2):164-170. DOI: $10.1164 / \mathrm{rccm} .200505-7180 \mathrm{C}$.
4. Ferrer M, Sellarés J, Valencia M, Carrillo A, Gozalez G, Badia JR, et al. Non-invasive ventilation after extubation in hypercapnic patients with chronic respiratory disorders: randomised controlled trial. Lancet 2009;374(9695):1082-1088. DOI: 10.1016/S01406736(09)61038-2.

5. Esteban A, Frutos-Vivar F, Muriel A, Ferguson ND, Penuelas $O$, Abraira $V$, et al. Evolution of mortality over time in patients receiving mechanical ventilation. Am J Respir Crit Care Med 2013;188(2):220230. DOI: $10.1164 / \mathrm{rccm} .201212-21690 \mathrm{C}$

6. Ghosh S, Chawla A, Jhalani R, Salhotra R, Arora G, Nagar S, et al. Outcome of prophylactic non-invasive ventilation following planned extubation in high-risk patients: 2-year prospective observational study from a general intensive care unit. Indian J Crit Care Med 2020;24(12):1185-1192. DOI: 10.5005/jp-journals-10071-23673.

7. Stéphan $F$, Barrucand $B$, Petit $P$, Rézaiguia-Delclaux $S$, Médard $A$, Delannoy $B$, et al. High-flow nasal oxygen vs non-invasive positive airway pressure in hypoxemic patients after cardiothoracic surgery. $A$ randomized clinical trial. JAMA 2015;313(23):2331-2339. DOI: 10.1001/ jama.2015.5213.

8. Hernandez G, Vaquero C, Colinas L, Cuena R, Gonzalez P, Canabal $A$, et al. Effect of post-extubation high-flow nasal cannula vs noninvasive ventilation on reintubation and post-extubation respiratory failure in high-risk patients: a randomized clinical trial. JAMA 2016;316(15):1565-1574. DOI: 10.1001/jama.2016.14194.

9. Thille AW, Muller G, Gacouin A, Coudroy R, Decavele M, Sonneville $\mathrm{R}$, et al. Effect of post-extubation high-flow nasal oxygen with noninvasive ventilation vs high-flow nasal oxygen alone on reintubation in patients at high risk of extubation failure. JAMA 2019;322(15):14651475. DOI: 10.1001/jama.2019.14901.

10. Ghosh S, Chawla A, Mishra K, Jhalani R, Salhotra R, Singh A. Cumulative fluid balance and outcome of extubation: a prospective observational study from a general intensive care unit. Indian J Crit Care Med 2018;22(11):767-772. DOI: 10.4103/ijccm.IJCCM_216_18.

11. Boles JM, Bion J, Connors A, Herridge M, Marsh B, Melot C, et al. Weaning from mechanical ventilation. Eur Respir J 2007;29(5):10331056. DOI: 10.1183/09031936.00010206.

12. Thille AW, Harrois A, Schortgen FD, Brun-Buisson C, Brochard L. Outcomes of extubation failure in medical intensive care unit patients. Crit Care Med 2011;39(12):2612-2618. DOI: 10.1097/ CCM.0b013e3182282a5a.

13. Esteban A, Frutos-Vivar F, Niall D, Arabi Y, Apezteguía C, González $M$, et al. Non-invasive positive-pressure ventilation for respiratory failure after extubation. N Engl J Med 2004;350(24):2452-2460. DOI: 10.1056/NEJMoa032736.

14. Truwit JD, Bernard GR. Non-invasive ventilation-Don't Push Too Hard. N Engl J Med 2004;350(24):2512-2515. DOI:_10.1056/ NEJMe048049.

15. Chawla R, Dixit SB, Zirpe KG, Chaudhry D, Khilnani GC, Mehta Y, et al. ISCCM guidelines for the use of non-invasive ventilation in acute respiratory failure in adult ICUs. Indian J Crit Care Med 2020;24(Suppl. 1): S61-S81. DOI: 10.5005/jp-journals-10071-G23186. 